\title{
44. SULFUR ISOTOPIC COMPOSITION IN DSDP LEG 37 CORES
}

\author{
H.R. Krouse and H.M. Brown, Department of Physics and R.B. Farquharson,
} Department of Geology, The University of Calgary, Calgary, Alberta, Canada

\section{INTRODUCTION}

Sulfur isotope composition can elucidate the genesis of sulfide-bearing minerals. In the current study, two isotopic reference points are important. Sulfides associated with magmatic-type hydrothermal deposits which may correspond to mantle-derived sulfur have isotopic compositions close to the meteoritic reference, i.e., $\delta^{34} \mathrm{~S} \approx 0 .^{1}$ Modern seawater sulfate is remarkably uniform isotopically with $\delta^{34} \mathrm{~S} \approx+20.3$ (Thode et al., 1961). Another important consideration is that isotopic selectivity by microorganisms during sulfate reduction may produce sulfides very enriched in the lighter ${ }^{32} \mathrm{~S}$.

\section{ANALYTICAL PROCEDURES}

The flow diagram for sample preparation is shown in Figure 1. In the case of igneous rocks, only mechanically separated pyrites were examined. For sediments, an ultrasonic organic extraction with $\mathrm{CCl}_{4}$ yielded very small colorless residues upon evaporation for which isotopic analyses were not feasible. The sulfate portion included free sulfate ion as well as crystallized sulfates capable of solution in $1.0 \mathrm{~N} \mathrm{HCl}$. The bulk of the residue from acid treatment was mainly fine pyrites with possible traces of nonsoluble components such as barite.

\section{RESULTS AND DISCUSSION}

\section{Sediments}

The isotope data for the sediments are given in Table 1 and Figures 2 and 3 as a function of approximate depth below sea bottom. The $\delta^{34} \mathrm{~S}$ values show large fluctuations with $\Delta^{0} / 00=\delta^{34} \mathrm{SO}_{4}=-\delta^{34} \mathrm{~S}=$ as large as $70^{\circ} \%$. Sulfate reduction during burial has realized large ${ }^{34} \mathrm{~S}$ depletions in pyrites of other sediments, but the $\Delta \%$ values of this report rank with the largest reported to date (Goldhaber and Kaplan, 1974, p. 637). Although a mass balance of the sulfur components is difficult because of the inhomogeneity, it is readily seen that the mean isotopic composition of many of the sediment samples is lighter than present-day seawater. In particular, if isotopically light sulfides are produced by sulfate reduction, the unreacted sulfate should become isotopically heavier. Although in our procedures acidsoluble sulfides could end up in the sulfate fraction, the lack of an $\mathrm{H}_{2} \mathrm{~S}$ odor during processing suggests that this was not the case. There are other observations that

$$
{ }^{1}{ }_{\delta^{34}} \mathrm{~S} \text { in } \%=\frac{\left[\mathrm{S}^{34} / \mathrm{S}^{32}-\right.\text { sample }}{\left[\mathrm{S}^{34} / \mathrm{S}^{32}-\right.\text { meteorite }} \times 1000 .
$$

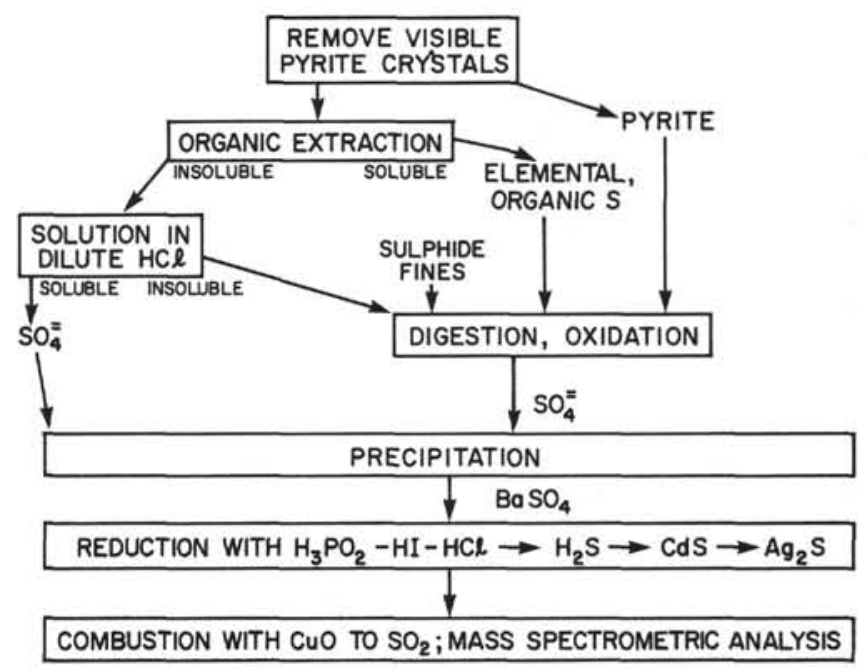

Figure 1. Flow diagram for sample preparation.

strongly suggest that the isotopic balance fluctuates considerably within a short distance. If relatively closely spaced samples 332B-1-1, 109-111 cm and 1-1, 74-76 $\mathrm{cm}$ are compared, it is seen that both the $\delta^{34} \mathrm{SO}_{4}=$ and $\delta^{34} \mathrm{~S}=$ values of the latter are roughly $12^{\circ} \%$ lighter than the former. In other words, the $\Delta^{\%} / 0$ values are similar, but the mean isotopic composition has shifted. At Site 335, Sample 4-3, $41-43 \mathrm{~cm}$ is interesting in that the $\delta^{34} \mathrm{SO}_{4}=$ value is very negative, ranking with the sulfides from that site. The pyrites associated with this sample are the most ${ }^{34} \mathrm{~S}$-depleted of all of the Site 335 samples analyzed. Since the sulfate concentration was low in this sample, this may indeed be a case where our sulfate portion contained acid-soluble sulfide. This sample is also interesting in that it contained larger pyrite crystals which were mechanically removed and their $\delta^{34} \mathrm{~S}$ values are about $3 \%$ lighter than the fine pyrites in the residue. This is consistent with sulfate reduction occurring after burial (Goldhaber and Kaplan, 1974, p. 638-640).

Another facet of the sulfur isotopic data for sulfates is that with the exception of the sample described above, the $\delta^{34} \mathrm{SO}_{4}=$ values for Site 335 increase with depth (Figure 2) so that the deeper samples have mean $\delta^{34} \mathrm{~S}$ values closer to present-day seawater. It is also interesting that Sample 332B-6-2, 77-80 cm, which is characterized as lithified or metamorphosed sediment, has a $\delta^{34} \mathrm{~S}$ value very close to the modern seawater mean.

In summary, the sulfur isotope data for the sediments attest to large and variable isotope fractionations during sulfate reduction after burial. The isotopic mean 
TABLE 1

DSDP Leg 37 Sulfur Isotope Data

\begin{tabular}{|c|c|c|c|c|c|}
\hline & $\begin{array}{c}\text { Sample } \\
\text { (Interval in } \mathrm{cm} \text { ) }\end{array}$ & $\begin{array}{l}\text { Approximate } \\
\text { Depth Below } \\
\text { Floor }(\mathrm{m})\end{array}$ & $\mathrm{SO}_{4}=$ & $\frac{\delta^{34} \text { S Values }}{\text { Residue }}$ & Pyrite \\
\hline $\begin{array}{l}\text { Hole 333A } \\
\text { sediments }\end{array}$ & $\begin{array}{l}3-2,22-24 \\
3-5,114-116 \\
4-1,109-111 \\
5-5,100-102\end{array}$ & $\begin{array}{l}246 \\
251 \\
264 \\
289\end{array}$ & $\begin{array}{l}+14.2 \\
-5.6 \\
+17.6 \\
+3.3\end{array}$ & $\begin{array}{l}-47.7 \\
-50.4 \\
-22.1\end{array}$ & \\
\hline $\begin{array}{l}\text { Hole 332B } \\
\text { sediments }\end{array}$ & $\begin{array}{l}1-1,74-76 \\
1-1,109-111 \\
1-2,116-117 \\
6-2,77-80\end{array}$ & $\begin{array}{l}143 \\
143 \\
145 \\
287\end{array}$ & $\begin{array}{l}+0.8 \\
+12.5 \\
+16.7 \\
+20.2\end{array}$ & $\begin{array}{l}-53.7 \\
-41.6\end{array}$ & \\
\hline $\begin{array}{l}\text { Site } 335 \\
\text { sediments }\end{array}$ & $\begin{array}{l}1-2,58-60 \\
2-5,103-105 \\
3-1,82-83 \\
4-3,41-43 \\
\\
4-3,101-106 \\
5-1,68-69 \\
5-1,111-114\end{array}$ & $\begin{array}{r}89 \\
132 \\
221 \\
319 \\
\\
\\
320 \\
448 \\
449\end{array}$ & $\begin{array}{l}+9.2 \\
+16.8 \\
+12.8 \\
-41.1 \\
+18.0 \\
+22.9 \\
+21.0\end{array}$ & $\begin{array}{l}-36.9 \\
-43.5 \\
-50.4 \\
-49.6 \\
-40.5 \\
-41.2\end{array}$ & $\begin{array}{l}-54.1 \\
-53.2\end{array} \mid$ \\
\hline $\begin{array}{l}\text { Hole } 333 \mathrm{~A} \\
\text { igneous rock }\end{array}$ & $\begin{array}{l}10-2,5-6 \\
10-2,50-53 \\
10-3,35-37 \\
10-3,80-83\end{array}$ & $\begin{array}{l}483 \\
484 \\
\\
485 \\
486\end{array}$ & & & $\begin{array}{l}-19.9 \\
-33.4 \\
-32.5 \\
-30.2 \\
-13.7\end{array}$ \\
\hline $\begin{array}{l}\text { Hole 332B } \\
\text { igneous rock }\end{array}$ & $\begin{array}{l}44-6,38-39 \\
44-6,51-52 \\
46-1,54-56 \\
46-1,97-98 \\
46-2,29-30\end{array}$ & $\begin{array}{l}681 \\
\\
682 \\
693 \\
694 \\
695\end{array}$ & & & $\begin{array}{c}-14.4 \\
-17.0 \\
-9.5 \\
-8.4 \\
-7.0 \\
-5.7 \\
-5.0 \\
-4.8\end{array}$ \\
\hline
\end{tabular}

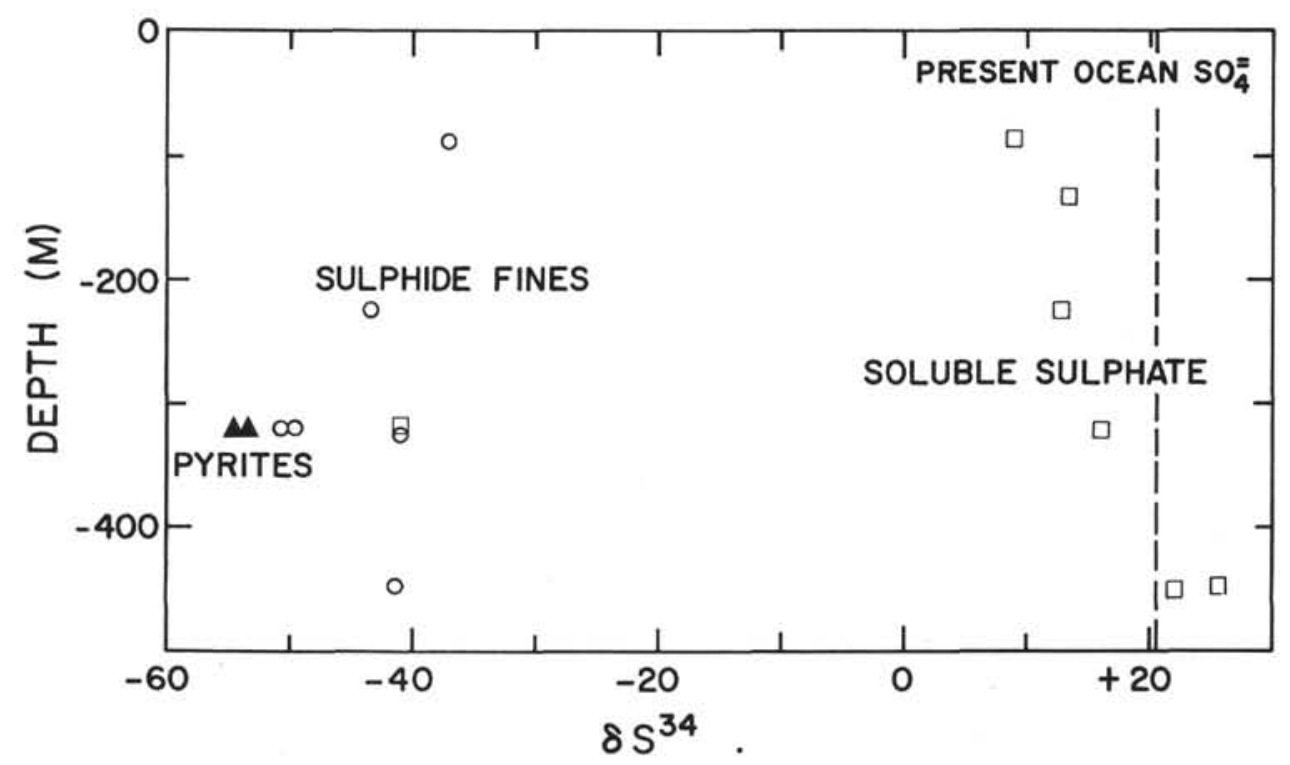

Figure 2. Sulfur isotope variations in sediments, DSDP Leg 37 Site 335.

values for the samples fluctuate considerably suggesting either an additional lighter isotopic source or large migrations of sulfur ions in the sediments. A more detailed investigation over the total depth is necessary to delineate these possibilities.

\section{Igneous Rocks}

The isotopic data for pyrites mechanically separated from the igneous rocks are given inTable 1 and Figure
4. It is interesting that the upper specimens display significant $\delta^{34} \mathrm{~S}$ depletions, although not to the extent found in the sediments. With increasing depth there is a trend towards $\delta^{34} \mathrm{~S}=0$, the range associated with magmatic sulfides. The limited data also display fewer $\delta^{34} \mathrm{~S}$ fluctuations with increasing depth. Although the data suggest seawater contributions in the upper igneous rocks, stratigraphic alignment of the cores and sampling over a broader range is desirable to elucidate 


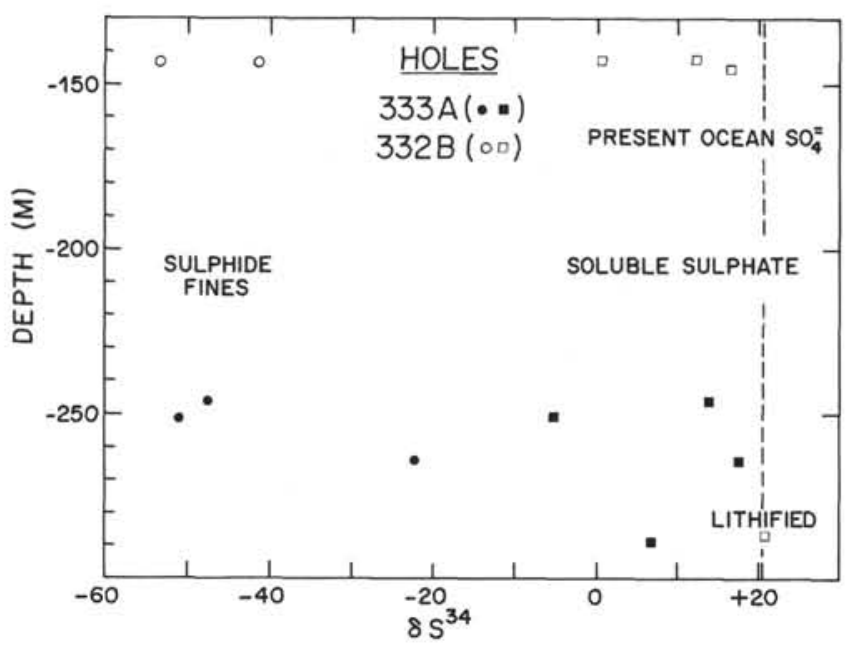

Figure 3. Sulfur isotope variations for sediments, DSDP Leg 37 , Holes $332 B$ and $333 A$.

these trends. This would also permit a comparison with oxygen and strontium isotope trends noted by Gray et al. (this volume).

\section{ACKNOWLEDGMENTS}

The technical assistance of Miss J. Pontoy and Miss N. Enojo, the financial support of the National Research Council of Canada in the form of a DAGS grant, and the assistance of all those who helped obtain samples are gratefully acknowledged.

\section{REFERENCES}

Goldhaber, M.B. and Kaplan, I.R., 1974. Marine chemistry, In Goldberg, E.D. (Ed.), The sea, v. 5: New York (John Wiley and Sons, Inc.).
D.S.D.P. 37 PYRITES

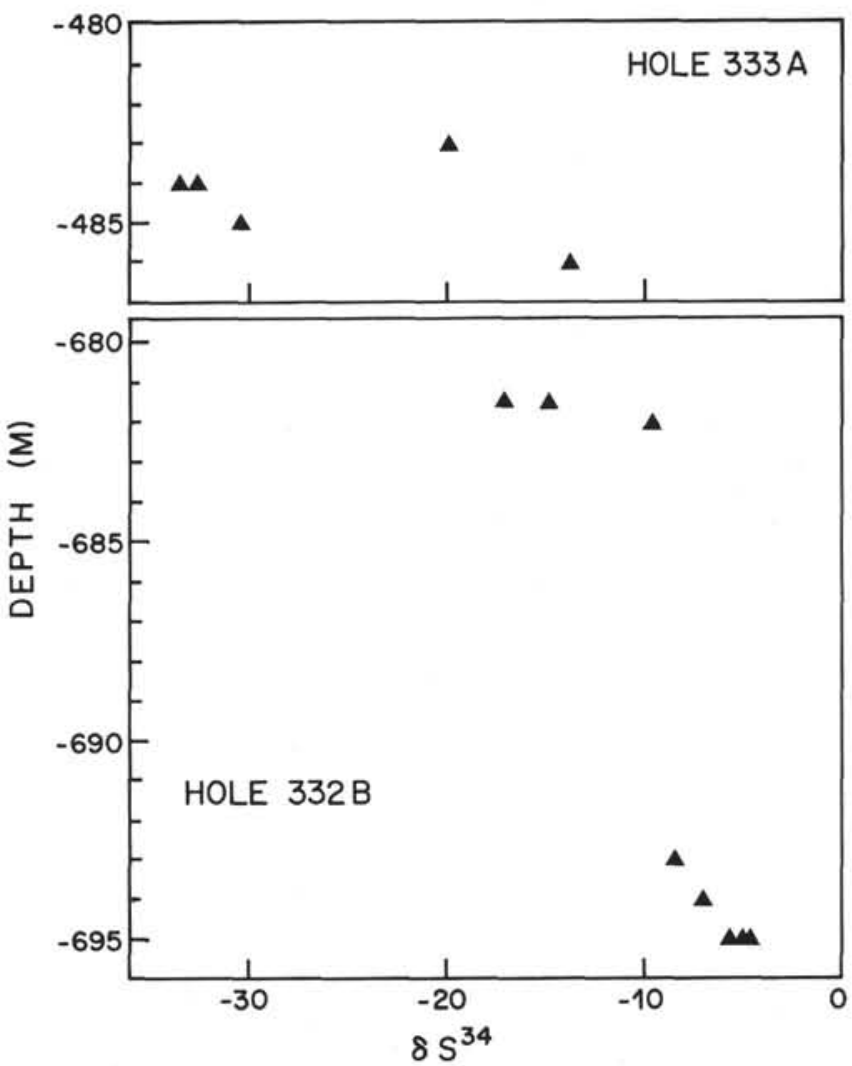

Figure 4. Sulfur isotope variations in igneous rocks, DSDP Leg 37, Holes $332 B$ and 333 A.

Thode, H.G., Monster, J., and Dunford, H.B., 1961. Sulfur isotope geochemistry: Geochim. Cosmochim. Acta, v. 25, p. 159-174. 